\title{
China's local governments are combating COVID-19 with unprecedented responses - from a Wenzhou governance perspective
}

\author{
Fanghua Gong ${ }^{1,2}$, Yong Xiong ${ }^{2}$, Jian Xiao ${ }^{1,2}$, Li Lin $^{1,2}$, Xiaodong Liu $^{3}$, Dezhong Wang ${ }^{2}$, Xiaokun Li $(\bowtie)^{1,2}$ \\ ${ }^{1}$ School of Pharmaceutical Sciences, Wenzhou Medical University, Wenzhou 325035, China; ${ }^{2}$ Biomedicine Collaborative Innovation Center, \\ Wenzhou 325035, China; ${ }^{3}$ School of Public Health and Management, Wenzhou Medical University, Wenzhou 325035, China
}

(C) Higher Education Press and Springer-Verlag GmbH Germany, part of Springer Nature 2020

\begin{abstract}
The COVID-19 caused by a novel strain of coronavirus has been spreading rapidly since its occurrence in December 2019. It is highly communicable through human-to-human transmission. China has been making unprecedented efforts in treating the confirmed cases, identifying and isolating their close contacts and suspected cases to control the source of infection and cut the route of transmission. China's devotion in handling this epidemic has effectively and efficiently curbed communication domestically and across the border. Representative measures adopted by Wenzhou, the worst hit city out of Hubei Province, are examined to elucidate those massive undertakings with the aim of enhancing international understanding and building global rapport in fighting this evolving epidemic situation.
\end{abstract}

Keywords COVID-19; novel coronavirus pneumonia; 2019-nCoV; epidemic management

\section{Introduction}

A novel strain of coronavirus has caused a pneumonia outbreak in the central Chinese city of Wuhan since December 2019 and has been quickly spreading to other parts of China. Sporadic cases are also identified in other countries and regions of the world.

Named as 2019 novel coronavirus (2019-nCoV) initially by the World Health Organization (WHO) in January 2020, it was a previously unknown pathogen and has escalated into an unprecedented outbreak. The pneumonia caused by this viral strain was named "novel coronavirus pneumonia" by China's National Health Commission on February 7 , 2020 [1] and later officially named internationally as COVID-19 on February 11, 2020 by the WHO [2]. As commented by the WHO Director-General Dr. Tedros Adhanom Ghebreyesus, the outbreak has been met by an unprecedented response [3] from the Chinese government and grassroot communities.

A total of 44730 confirmed and 16067 suspected

Received February 12, 2020; accepted February 13, 2020

Correspondence: Xiaokun Li, lixk1964@163.com
COVID-19 cases have been reported in China with 4742 cured and 1114 deaths by midnight of February 11, 2020 [4] and an additional 441 confirmed cases overseas with 1 death in the Philippines as of 17:30 on February 12, 2020 [5]. The trends in confirmed cases, suspected cases, and deaths that resulted from this disease are shown in Figs. 1-3, respectively. The world is in a race against time to identify the root cause and find a vaccine for this new virus, and China is taking the lead in this combat as the worst hit country.

The world may be well informed of the amazing speed of the Chinese in constructing and manning two purposebuilt hospitals in Wuhan, the epicenter of the virus outbreak. The two dedicated hospitals, Huoshenshan (Fire God Mountain) Hospital with 1000 beds and Leishenshan (Thunder God Mountain) Hospital with 1600 beds, only took 9 and 14 days to complete from scratch, respectively, and were staffed with medics from hospitals affiliated to the People's Liberation Army (PLA) Joint Logistic Support Force and medical universities of the army, navy, and air force of the PLA [6]. The two makeshift hospitals are playing major roles in improving the cure rate and decreasing the death rate of infected patients and help China and the world win the combat of 


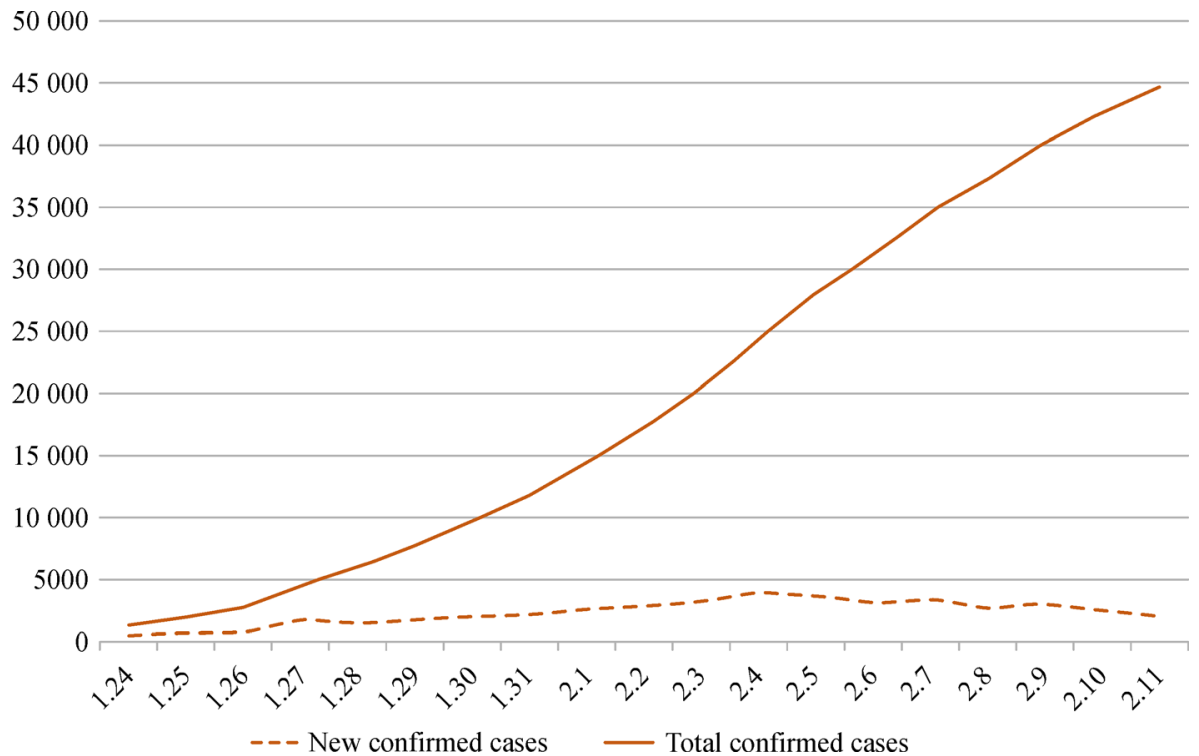

Fig. 1 Trend of confirmed COVID-19 cases in Chinese mainland from January 24 to February 11, 2020 (Data source: Official website of National Health Commission of the People's Republic of China).

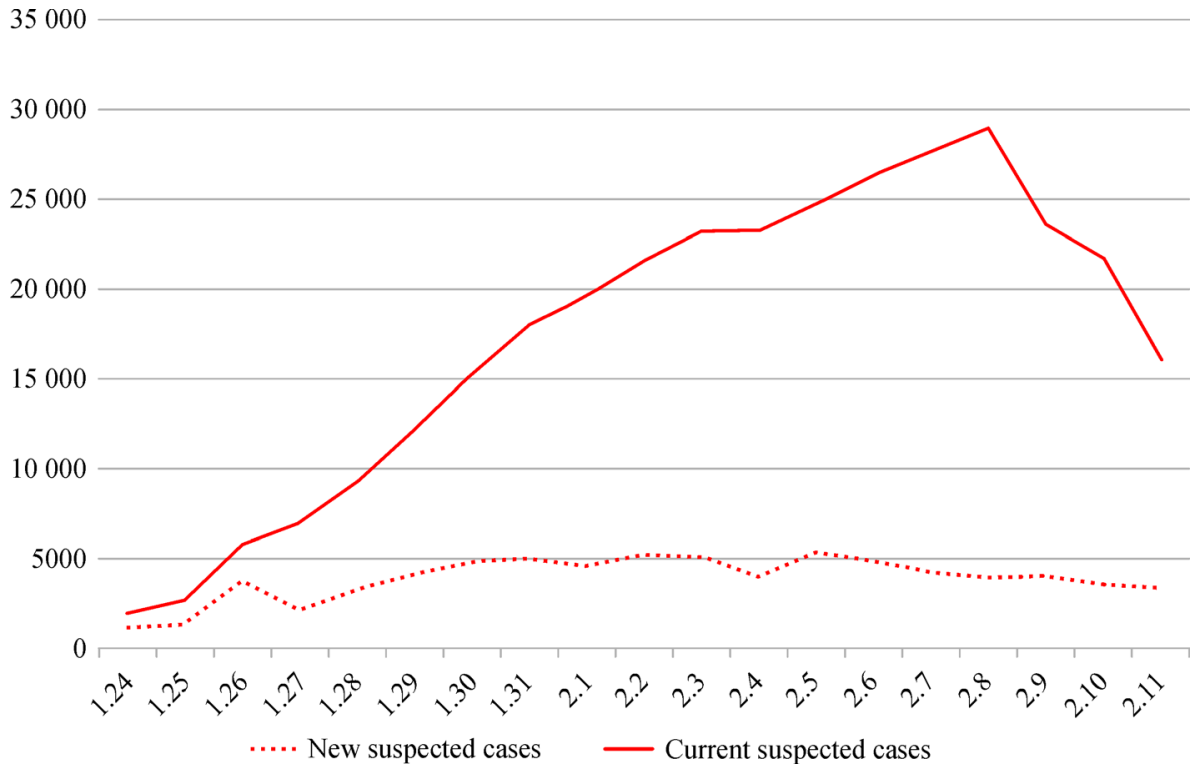

Fig. 2 Trend of suspected COVID-19 cases in Chinese mainland from January 24 to February 11, 2020 (Data source: Official website of National Health Commission of the People's Republic of China).

prevention against and control of this growing epidemic situation. Although this event is extremely impressive, the strategy and measures taken by Wenzhou merit special attention and even commendation.

\section{Rigorous measures rolled out overnight in cutting off routes of transmission in Wenzhou}

Wenzhou, a city $900 \mathrm{~km}$ away from Wuhan and well- known for its private economy and entrepreneurial spirits of its people, is again catching the whole nation's attention as the worst hit place second only to Hubei Province by COVID-19. Statistics show that almost 180 thousand Wenzhou people were in Wuhan for business or study in 2019 , and over 78.8 thousand of them returned to Wenzhou for the traditional Chinese Spring Festival at a time when the virus was announced and the city of Wuhan was placed into full lockdown. Consequently, the effective control of the source of the virus and efficient prevention of internal communication became a paramount challenge for 


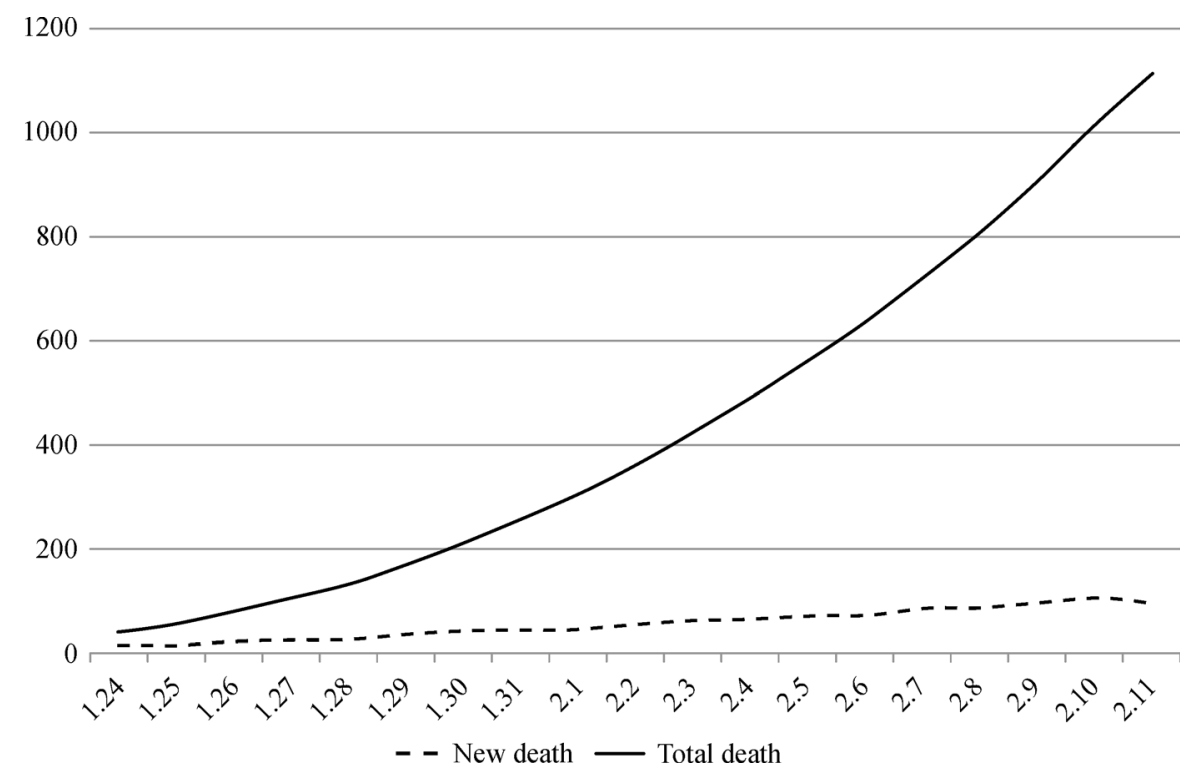

Fig. 3 Trend of COVID-19-caused deaths in Chinese mainland from January 24 to February 11, 2020 (Data source: Official website of National Health Commission of the People's Republic of China).

the city.

In response to the Chinese Central Government's mandate, Wenzhou's municipal government convened emergency meetings (mostly through video conferences to avoid mobility and contact) in the last weeks to deliberate on coping policies, preventive measures, and implementation plans with objective investigation and across-the-board examination of the rapidly worsening epidemic reality. On January 29, the municipal government convened a video conference pledging to curb the deterioration of the epidemic situation and reach the inflection point by making concerted efforts and working vigorously for 10 days [7] until the Lantern Festival, a day when the traditional Chinese Spring Festival officially ends.

In the evening of January 31, the municipal government rolled out "Twenty-five Emergency Measures" that cover the control measures for human mobility, traffic, and daily necessity outlets and the prevention and control measures for post-holiday work and production resumption. Those measures include: postponing resumption of production for various enterprises until February 17 except for those closely related to public utilities, everyday life supply, epidemic prevention and control, or concerning national interest and people's livelihood; postponing resumption of work for public institutions until February 9 except for those involved in epidemic prevention and control; postponing resumption of school until March 1 for all levels and categories of educational institutions and organizations; temporary suspension of all city bus and metro lines; strict checking arrangement for all private houses and public places; requirement of wearing protective face masks when one has to go out; closure of badly affected villages, communities, and residential areas; cancellation of all public fairs and large gatherings and closing of parks, libraries, museums, cinemas, swimming pools, large department stores, and commercial complexes; closing of central air-conditioning at densely populated areas; reward for reporting to municipal authorities of hiding patients or suspected individuals secretly returning from Hubei.

Since January 24, nine circulars had been issued by Wenzhou Municipal Leading Group for COVID-19 Prevention and Control, which was headed by the mayor. The latest circular issued on February 9 announced measures with even elevated rigidness to curb possible COVID-19 transmission at famer markets and supermarkets. Measures from previous circulars include: body temperature monitoring, daily sterilization, and improving ventilation at high-density public places such as airport, train and bus stations, passenger piers, and expressway entrances and exits (Circular 1, January 24); 24/7 whistleblowing hotline for reporting to Municipal Epidemic Prevention and Control Office of recent returnees from Hubei Province who were not quarantined for medical observation (Circular 2, January 25); strengthening of management and control of 14-day home or concentrated quarantine (at designated hotels by arranging government purchase of services with medical staff and resources deployed) for source of risks including all returnees from Hubei Province, their close contacts, and patients with fever, with one-to-one follow-up and tracking scheme in place (Circular 3, January 27) (see Fig. 4 for total number of close contacts subsequently traced); heightened control 


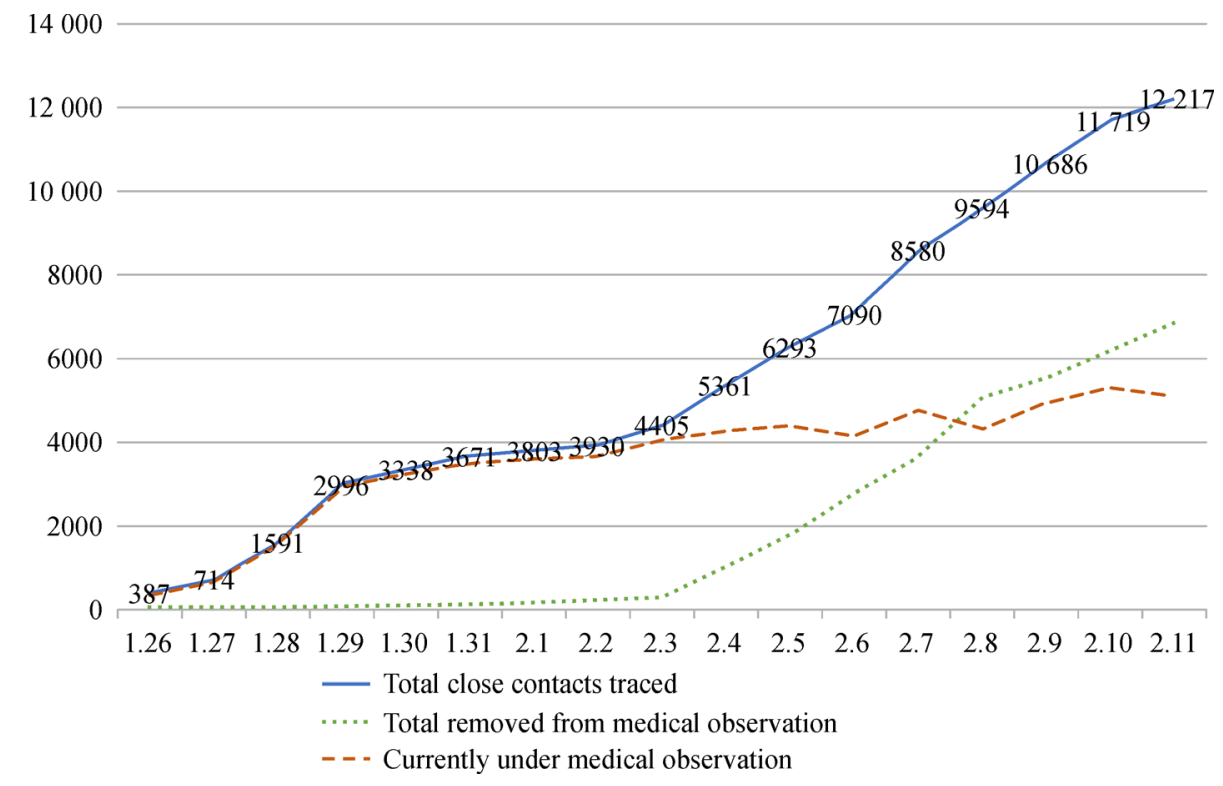

Fig. 4 Number of traced close contacts with COVID-19 patients or suspects and those subsequently placed under medical observation in Wenzhou from January 26 to February 11, 2020 (Data source: Official website of Wenzhou Municipal People's Government).

of household mobility by allowing only one family member to go out for daily necessity shopping every other day (Circular 6, February 1); and temporarily closing 46 expressway entrances and exits within its administration, keeping only 9 with one for each district or township under its jurisdiction (Circular 7, February 2).

\section{Wenzhou is setting a new model for epidemic outbreak response}

Updated measures followed the above policies considering the development of the actual circumstances. The battery of rigorous measures had been appropriate given the gravity of the situation and proved timely and conducive to the effective prevention and control of this epidemic in Wenzhou. There had been an evident decrease in newly confirmed cases (illustrated in Fig. 5 in dotted line). Thus, the total number of confirmed cases is leveling out recently.

Wenzhou people are known far and wide as people with entrepreneurship, determination, and collective spirits. With this conjuncture, Wenzhou is demonstrating outstanding organizing and coping capacities in the face of unexpected crisis and showing the rest of the country that a war of defense against COVID-19 had been waged. Furthermore, the city is on the right track to containment and recovery. Similar mass mobilization and harsh measures are under way in severely affected areas in China to ensure the health and safety of people, both Chinese and internationals, and the effective prevention and control of this epidemic for the shared well-being of mankind.

Like any other unexpected outbreak, COVID-19 caused fear, anxiety, and panic locally, nationally, and globally. The good news is that China's response on how to combat and stop the spread of the coronavirus had been undoubtedly swift and amazing as WHO Director-General Dr. Tedros Adhanom Ghebreyesus noted: "I will praise China again and again because its actions actually helped in reducing the spread of the novel coronavirus to other countries ... In many ways, China is actually setting a new standard for outbreak response. It's not an exaggeration." [3]

"The nation is currently experiencing a peak period of confirmed cases. With prevention and control measures in place, the number of future infections will be significantly reduced," said Li Lanjuan, a renowned Chinese epidemiologist and academician of the Chinese Academy of Engineering.

\section{Conclusions}

As the virus is highly contagious, the entire world is looking to China's prevention and control efforts. Wenzhou has been taking timely, rigorous, and systematic measures in fighting the spread of this epidemic within its jurisdiction. The unprecedented responses prove effective and efficient in curbing the source of infection and cutting the route of transmission and are setting new standards for other cities to overcome the challenge and difficulties together.

Chinese President Xi Jinping has stressed releasing 


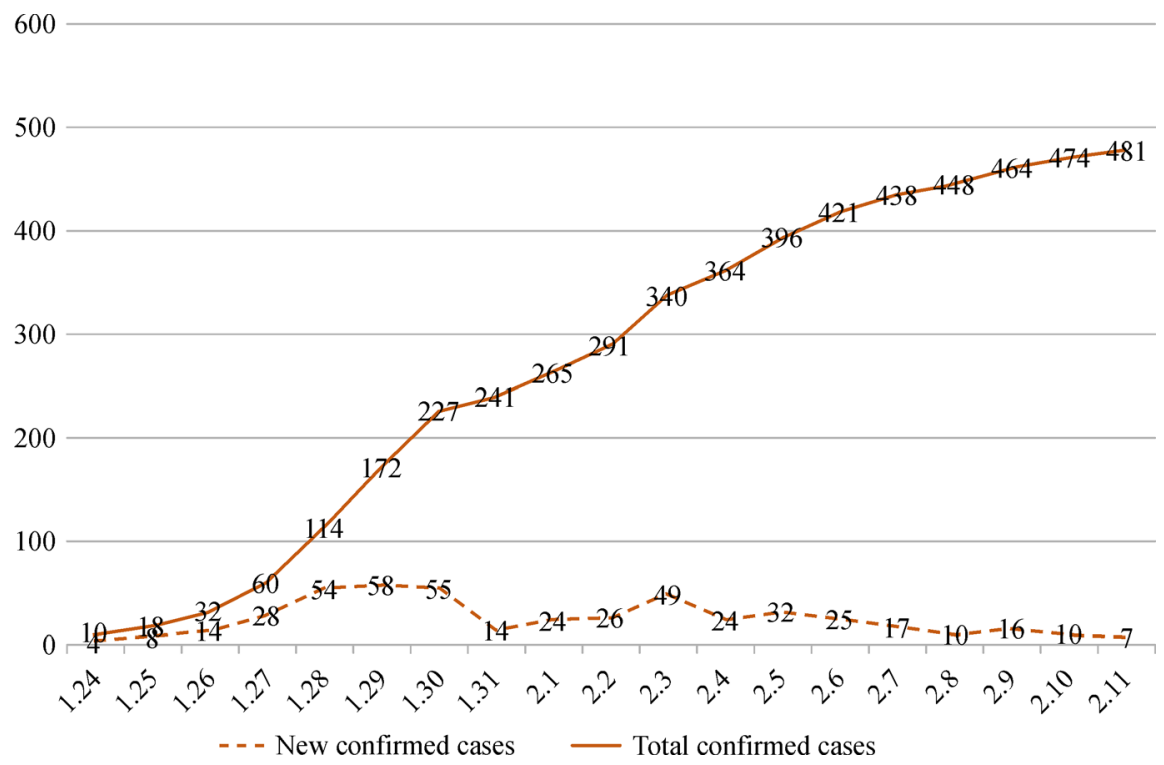

Fig. 5 Number of confirmed COVID-19 cases in Wenzhou from January 24 to February 11, 2020 (Data source: Official website of Wenzhou Municipal People's Government).

information in a timely manner and deepening international cooperation to fight this crisis. When meeting with WHO Director-General Dr. Ghebreyesus, Xi stressed that China is ready to work with the WHO and the international community to safeguard regional and global public health security [8].

In a deeply interwoven world, the only way we will defeat this outbreak is for all countries to work together in a spirit of solidarity and cooperation. This is the time for facts, not fear. This is the time for science, not rumors. We, as a global community with a shared future, are all in this combat together. Together, we must and we will win this fight.

\section{Compliance with ethics guidelines}

Fanghua Gong, Yong Xiong, Jian Xiao, Li Lin, Xiaodong Liu, Dezhong Wang, and Xiaokun Li declare no conflicts of interest. This article does not involve a research protocol requiring approval by the relevant institutional review board or ethics committee.

\section{References}

1. National Health Commission of the People's Republic of China. Notice by National Health Commission on the Provisional Designation of Novel Coronavirus Pneumonia. 2020. http://www.nhc.gov.cn/ yzygj/s7653p/202002/18c1bb43965a4492907957875de02ae7.shtml (in Chinese) (accessed February 8, 2020)

2. World Health Organization. Novel Coronavirus (2019-nCoV) Situation Report - 22. 2020. https://www.who.int/docs/default-source/ coronaviruse/situation-reports/20200211-sitrep-22-ncov.pdf?sfvrsn = fb6d49b1_2 (accessed February 12, 2020)

3. World Health Organization. WHO Director-General's statement on IHR Emergency Committee on Novel Coronavirus (2019-nCoV). 2020. https://www.who.int/dg/speeches/detail/who-director-generals-statement-on-ihr-emergency-committee-on-novel-coronavirus(2019-ncov) (accessed February 3, 2020)

4. National Health Commission of the People's Republic of China. Latest update on Novel Coronavirus Pneumonia as of 24:00, February 11, 2020. 2020. http://www.nhc.gov.cn/xcs/yqfkdt/ 202002/395f075a5f3a411f80335766c65b0487.shtml (in Chinese) (accessed February 12, 2020)

5. Tencent News. Real-time update: Latest on COVID-19. 2020. https:// news.qq.com/zt2020/page/feiyan.htm (in Chinese) (accessed February 12,2020$)$

6. XINHUA. Makeshift hospital in Wuhan receives coronavirusinfected patients. 2020. http://www.xinhuanet.com/english/2020-02/ 08/c_138766645.htm (accessed February 8, 2020)

7. Wenzhou Municipal Health Commission. Fight ten days for the inflection point! Wenzhou sounds the bugle call to beat epidemic spread. 2020. http://wjw.wenzhou.gov.cn/art/2020/1/29/ art_1209919_41860600.html (in Chinese) (accessed February 3, 2020)

8. XINHUA. Commanding China's fight against novel coronavirus outbreak. 2020. https://www.chinadaily.com.cn/a/202002/02/ WS5e36ab70a310128217274329.html (accessed February 3, 2020) 